\title{
Cultivar differences in the operation of the photosystem II of barley leaves
}

\author{
Eugene Lisitsyn*, Svetlana Churakova, and Irina Shchennikova \\ Federal Agricultural Research Center of the North-East named N.V. Rudnitsky, 610007, 166 a, \\ Lenina st., Kirov, Russian Federation
}

\begin{abstract}
Differences between nine spring barley cultivars on structural and functional parameters of PSII operation are shown. Variability of the parameters used changed from 2.2...2.5 (oxidized quinones pool and maximum photochemical efficiency) to $24.6 \%$ (performance index PI ABS $\left._{\text {total }}\right)$. Parameters characterizing the values of excitation energy fluxes (ABS/RC; TRo/RC; ETo/RC) varied to a small extent - 3.1...6.5\%, while the lost energy (DIo/RC) much stronger - 14.6\%. The efficiency of electron transport from quinine $\mathrm{Q}_{\mathrm{B}}$ and the entire PSII until the PSI's primary acceptors varied even more -18.1 and $17.4 \%$, respectively. The $\mathrm{PI}_{\mathrm{ABS}}$ integral performance index combined cultivars into two groups only; $\mathrm{PI}_{\mathrm{ABS}}$ total index showed more clear differences in cultivars. Cv. Novichok and Fermer were significantly inferior to cv. Forward, Belgorodsky 100, Boyarin and Bionic in most of the studied parameters. However, according to the results of a cluster analysis, cv. Novichok and Forward turned out to be similar to each other, as well as cv. Fermer, Boyarin and Bionic, which separated into the same cluster. Probably, the action of PSII in cultivars of the same cluster differs only quantitative but not qualitative. Therefore, for breeding work on pyramidizing the genes controlling operation of this photosystem, it is advisable to crossing cultivars belonging to different clusters.
\end{abstract}

\section{Introduction}

The level of photosynthetic reactions is a good measure of the total plant productivity. Therefore, evaluating activity of the photosynthetic apparatus can significantly simplify and accelerate the process of plant phenotyping. Today, the fastest and most economical method of measuring the photosynthetic processes of plants is the method of assessing chlorophyll fluorescence. Chlorophyll a ( $\mathrm{Chl}$ a) fluorescence is a measure of the energy of absorbed light quants that have not been used in photosynthesis or dissipated as heat [1]. In normal and efficient operation of the photosystem 2 (PSII), the intensity of chlorophyll a fluorescence remains low, and any disruption of the photosynthesis process leads to its significant increase [2]. Measurements of parameters of chlorophyll a rapid fluorescence induction give a large amount of information about the operation of PSII in a relatively short time (several minutes). In recent years, the measurement of Chl a fluorescence, in

\footnotetext{
*Corresponding author: edaphic@mail.ru
} 
particular the JIP test has become a popular method for assessing the stability of photosynthesis under the influence of various stress factors of both abiotic and biotic nature [3]. For example, the change in the parameters of rapid fluorescence of barley leaves under the influence of drought has been studied in $[4,5]$; under the influence of high temperature - in [6], under the influence of salinity - in [7]. The effect of heavy metal ions on the action of barley PSII was studied by [8]; the level of chlorophyll fluorescence correlated with the barley lodging resistance index in [9]. On the example of two barley cultivars, [10] estimated the influence of different intensity of light, high and low temperature, cadmium, lead, chloride salinity, deficiency of macro- and microelements of nutrition on the activity of PSII. The authors confirmed the suitability of some chlorophyll fluorescence parameters as biomarkers for screening the level of plants resistant to these stressors. Some articles are published showing the effectiveness of this technique in assessing the level of resistance against fusariosis in some agricultural species including barley [11].

In general, such studies provide important information on the state of photosystem II (PSII) and its photochemical efficiency, on the amount of light quant energy captured by PSII reaction centers during photosynthesis, the unproductive costs of captured energy, the number of active and inactive reaction centers, and the efficiency of electron transfer in the electron transport chain of chloroplasts. However, such parameters are rarely used in assessing the production potential of plants under normal conditions. Biological resistance to stress does not always result in a final yield advantage expressed in absolute rather than relative values. Therefore, it is important to assess and compare the normal levels of functioning of photosystem 2 in different genotypes, to identify the causes of differences between cultivars and to use this data in the breeding work to increase plant productivity in specific growing conditions.

Based on this, the main tasks of the presented work were: to evaluate the levels of genotypic variability of various parameters of $\mathrm{Chl}$ a rapid fluorescence in spring barley leaves and to compare different genotypes according to the most variable evaluation parameters.

\section{Methods}

The object of the study was nine barley cultivars: Belgorodsky 100, Bionic, Boyarin, Dobryak, Novichok, Pamiaty Rodinoy, Rodnik Prikamiya, Fermer and Forward. Two-week seedlings grown on full nutrient solution at a photoperiod of 16/8 hours (day/night) and room temperature were used to evaluate the kinetics of chlorophyll fluorescence induction. Chl a fluorescence was recorded on dark-adapted (20 minutes) leaves using a Fluor Pen FP 110/S fluorometer (Photon Systems Instruments, Czech Republic) according to the manufacturer's guidelines. Induction fluorescence curves of $\mathrm{Chl}$ a were initiated with red light $(\lambda=650 \mathrm{~nm})$ intensity of $3,000 \mu \mathrm{mol} \mathrm{m}-2 \mathrm{~s}-1$. The following parameters of $\mathrm{Chl} \mathrm{a}$ fluorescence kinetics were evaluated and calculated: Fo (minimal fluorescence when all PSII reaction centers are assumed to be open); Fm (maximal fluorescence when all reaction centers of PSII are closed); tFm (time to reach Fm); Fv (maximal variable fluorescence); $\mathrm{Fv} / \mathrm{Fm}$ (maximal quantum yield of PSII); Fv/Fo (ability of antenna complexes to capture excitation energy); $\psi_{\mathrm{o}}$ (efficiency of electron transfer from $\mathrm{Q}_{\mathrm{A}}$ to $\mathrm{QB}$ ); $\delta_{\mathrm{RE}}$ (efficiency of electron transfer from $\mathrm{Q}_{\mathrm{B}}$ until PSI acceptor); $\psi_{\mathrm{RE}}$ (summering efficiency of electron transfer from PSII until PSI acceptor); specific energy fluxes per one reaction center of PSII (ABS/RC - light energy absorption flux; TRo/RC - maximum trapped exiton flux; $\mathrm{ETo} / \mathrm{RC}$ - electron transport flux from $\mathrm{Q}_{\mathrm{A}}$ to $\mathrm{Q}_{\mathrm{B}}$; DIo/RC - energy dissipation flux); performance Index for energy conservation from absorbed photons to the reduction of $\mathrm{Q}_{\mathrm{B}}$ $\left(\mathrm{PI}_{\mathrm{ABS}}\right)$ or of PSI acceptors ( $\left.\mathrm{PI}_{\mathrm{ABS} \_ \text {total }}\right)$. 
The obtained data were processed using descriptive statistics (Microsoft Office Excel 2007 software packages). The tables show the average data of threefold repetitions; the significance of differences between cultivars was assessed by the Duncan's criterion at $\mathrm{p} \leq$ 0.05. Cluster analysis was performed using StatSoft Statistica 10.0.

\section{Results}

The initial fluorescence of chlorophyll in the studied set of barley cultivars varied from 7,331 (cv. Rodnik Prikamiya) to 9,937 arbitrary units (cv. Boyarin) and averaged 8,480 \pm 765 arbitrary units (Figure 1A). The variability of this parameter was small $-9.0 \%$.

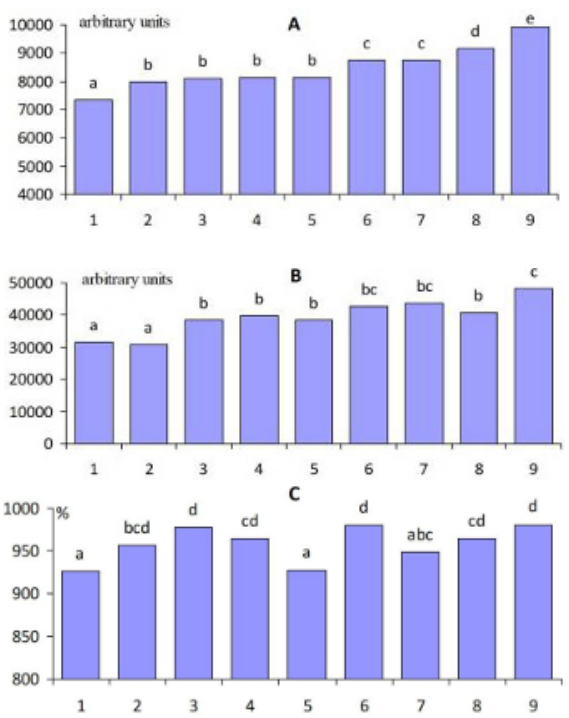

Fig. 1. Values of initial (A), maximum (B) Chl a fluorescence and time (milliseconds) to achieve maximum fluorescence (C) of barley cultivars: 1 - Rodnik Prikamiay; 2 - Novichok; 3 - Fermer: 4 Dobryak; 5 - Pamiaty Rodinoy; 6 - Bionic; 7 - Forward; 8 - Belgorodsky 100; 9 - Boyarin; identical letters show no statistically significant differences between cultivars.

In the first five cultivars in Figure 1A, the value of the initial fluorescence (Fo) was statistically significantly lower, i.e. light-harvesting complexes of PSII work more efficiently than in the rest of the cultivars. The studied cultivars were similar according to the parameter "maximum fluorescence" (Fm) (Figure 1B), however, the cv. Boyarin again shown the maximum value of the parameter, and the cv. Rodnik Prikamiya shown the minimum. The average value for the sample set was $39,476 \pm 1,855$ arbitrary units with a coefficient of variation equal to $14.1 \%$.

The cv. Rodnik Prikamiya and Pamiaty Rodinoy were statistically significantly inferior to the cv. Fermer, Bionic and Boyarin in terms of speed of electron transport within PSII estimated as time to achieve maximum fluorescence (Figure 1C).

The data in Table 1 show that when growing barley plants of the studied cultivars on full nutrient solution for 14 days, the average level of parameter "maximal photochemical efficiency" (Fv/Fm) was $0.786 \pm 0.019$.

Table 1. Performance of activity of antenna complexes and reaction centers in photon capture and efficiency of electron transfer in PSII.

\begin{tabular}{cccccc}
\hline Cultivar & Fv/Fm & Fv/Fo & $\psi_{o}$ & $\delta_{R E}$ & $\psi_{R E}$ \\
\hline Forward & 0.799 ef & 3,98 ef & 0.608 ef & $0.335 \mathrm{~cd}$ & $0.203 \mathrm{bc}$
\end{tabular}




$\begin{array}{llllll}\text { Fermer } & 0.790 \mathrm{~cd} & 3,78 \mathrm{c} & 0.595 \mathrm{cde} & 0.300 \mathrm{a} & 0.179 \mathrm{a} \\ \text { Belgorodsky } 100 & 0.801 \mathrm{f} & 4,04 \mathrm{f} & 0.667 \mathrm{~g} & 0.339 \mathrm{~d} & 0.228 \mathrm{~d} \\ \text { Bionic } & 0.795 \mathrm{de} & 3,89 \mathrm{e} & 0.623 \mathrm{f} & 0.304 \mathrm{a} & 0.189 \mathrm{ab} \\ \text { Boyarin } & 0.795 \mathrm{de} & 3,89 \mathrm{de} & 0.574 \mathrm{~b} & 0.322 \mathrm{c} & 0.185 \mathrm{a} \\ \text { Dobryak } & 0.796 \mathrm{ef} & 3,90 \mathrm{e} & 0.571 \mathrm{~b} & 0.321 \mathrm{bc} & 0.184 \mathrm{a} \\ \text { Novichok } & 0.741 \mathrm{a} & 2.91 \mathrm{a} & 0.602 \mathrm{de} & 0.436 \mathrm{f} & 0.263 \mathrm{e} \\ \text { Rodnik Prikamiya } & 0.768 \mathrm{~b} & 3.32 \mathrm{~b} & 0.586 \mathrm{bcd} & 0.488 \mathrm{~g} & 0.283 \mathrm{f} \\ \text { Pamiaty Rodinoy } & 0.788 \mathrm{c} & 3.75 \mathrm{c} & 0.545 \mathrm{a} & 0.387 \mathrm{e} & 0.209 \mathrm{c} \\ \text { Coefficient of } & 2.5 & 9.9 & 5.9 & 18.1 & 17.4 \\ \text { variation, \% } & & & & \end{array}$

Note: the values followed by the same letters do not differ statistically according to the Duncan's test at $\mathrm{p} \leq 0.05$.

Despite the low level of variability $(\mathrm{CV}=5.9 \%)$, statistically significant differences in a number of cultivars can be noted: the lowest value (and therefore the lowest activity of reaction centers) was noted in cv. Novichok $(0.741)$ and the largest (more active reaction centers) in cv. Forward, Dobryak and Belgorodsky 100 (0.796...0.801).

The variability of Fv/Fo parameter (Table 1 ) in the cultivar set under study was $9.9 \%$; leaf chlorophylls of the $\mathrm{cv}$. Novichok were the least capable of capturing photons $(\mathrm{Fv} / \mathrm{Fo}=$ $2.91)$, and the cv. Forward and Belgorodsky 100 were the most capable $(\mathrm{Fv} / \mathrm{Fo}=3.98$ and 4.04).

In terms of the efficiency of electron transfer from the primary (plastoquinone $\mathrm{Q}_{\mathrm{A}}$ ) to the secondary (plastoquinone $\left.\mathrm{Q}_{\mathrm{B}}\right)$ acceptor of the PSII $\left(\psi_{\mathrm{o}}\right.$ index) cv. Novichok was at the same level as cv. Forward and inferior only $9.7 \%$ to the cv. Belgorodsky 100 . At the same time, the efficiency with which electrons are transmitted from the PSII secondary acceptor $\left(\mathrm{Q}_{\mathrm{B}}\right)$, and in general from PSII to the PSI primary acceptors (indices $\delta_{\mathrm{RE}}$ and $\psi_{\mathrm{RE}}$ ) in the cv. Novichok was one of the highest, significantly exceeding the cv. Forward (by 30.1 and $29.5 \%$ ) and Belgorodsky 100 (by 28.6 and 15.4\%). The lowest electron transfer efficiency between plastoquinones $\mathrm{Q}_{\mathrm{A}}$ and $\mathrm{Q}_{\mathrm{B}}$ was noted in the cv. Pamiaty Rodinoy, the highest for the cv. Belgorodsky 100; the most effective transfer of electron from plastoquinone $\mathrm{Q}_{\mathrm{B}}$ until PSI primary acceptors occurred in the cv. Novichok; it was $45.3 \%$ higher than that of the most inefficient cv. Fermer. In general, the transfer of electrons from PSII to PSI was most effective in chloroplasts of the cv. Rodnik Prikamiay, the most ineffective in the cv. Fermer.

Processes characterizing the photosynthetic activity of PSII can be described in terms of specific energy fluxes calculated per active reaction center (Table 2).

Table 2. Specific energy fluxes per active reaction center of PSII.

\begin{tabular}{lllll}
\hline \multicolumn{1}{c}{ Cultivar } & \multicolumn{1}{c}{$\mathrm{ABS} / \mathrm{RC}$} & \multicolumn{1}{c}{$\mathrm{TRo} / \mathrm{RC}$} & \multicolumn{1}{c}{$\mathrm{ETo} / \mathrm{RC}$} & \multicolumn{1}{c}{$\mathrm{DIo} / \mathrm{RC}$} \\
\hline Forward & $2.082 \mathrm{ab}$ & $1.664 \mathrm{ab}$ & $1.012 \mathrm{c}$ & $0.418 \mathrm{ab}$ \\
Fermer & $2.044 \mathrm{a}$ & $1.632 \mathrm{a}$ & $0.970 \mathrm{a}$ & $0.412 \mathrm{a}$ \\
Belgorodsky 100 & $2.170 \mathrm{bcd}$ & $1.736 \mathrm{bcde}$ & $1.148 \mathrm{f}$ & $0.435 \mathrm{abc}$ \\
Bionic & $2.158 \mathrm{bcd}$ & $1.716 \mathrm{bcde}$ & $1.070 \mathrm{de}$ & $0.442 \mathrm{bc}$ \\
Boyarin & $2.241 \mathrm{~d}$ & $1.781 \mathrm{de}$ & $1.019 \mathrm{c}$ & $0.460 \mathrm{~cd}$ \\
Dobryak & $2.113 \mathrm{abc}$ & $1.681 \mathrm{abc}$ & $0.958 \mathrm{a}$ & $0.432 \mathrm{ab}$ \\
Novichok & $2.421 \mathrm{e}$ & $1.788 \mathrm{e}$ & $1.072 \mathrm{e}$ & $0.633 \mathrm{f}$ \\
Rodnik Prikamiya & $2.187 \mathrm{~cd}$ & $1.678 \mathrm{abc}$ & $0.984 \mathrm{abc}$ & $0.508 \mathrm{e}$ \\
Pamiaty Rodinoy & $2.222 \mathrm{~d}$ & $1.749 \mathrm{cde}$ & $0.946 \mathrm{a}$ & $0.474 \mathrm{~d}$ \\
Coefficient of variation, & $\mathrm{d} .0$ & 3.1 & 6.5 & 14.6 \\
$\%$ & & & & \\
\hline
\end{tabular}

Note: the values followed by the same letters do not differ statistically according to the Duncan's test at $\mathrm{p} \leq 0.05$. 
The energy flux absorbed by one reaction center (ABS/RC index) was a fairly stable parameter $(\mathrm{CV}=5.0 \%)$ in studied set of barley cultivars. However in plants of the $\mathrm{cv}$. Novichok, reaction centers are provided with a highest number of antenna pigments, and in the cv. Forward and Fermer - the smallest; the difference is $16.3 \ldots 18.4 \%$. However, at the same time, the cv. Novichok has the highest ineffective costs of energy (for radiation in the form of heat and fluorescence - the DIo/RC index); the cv. Fermer, Forward, Dobryak and Belgorodsky 100 spend $31.3 \ldots 34.9 \%$ less energy on thermal radiation. On average for studied set of barley cultivars, $21.4 \%$ of the energy absorbed by antenna complexes is spent on thermal and fluorescent radiation.

In absolute values, the energy flux stored in the form of free energy in primary photochemical reactions and denoted as TRo/RC index is approximately equal in magnitude to the cv. Novichok, Belgorodsky 100, Bionic, Boyarin and Pamiaty Rodinoy. However, if one expresses it as a percentage of the absorbed energy, then in the cv. Novichok it will be only $74 \%$, in the remaining four varieties $-79 \ldots 80 \%$.

The flux of electronic transport ETo/RC, which ultimately leads to $\mathrm{CO}_{2}$ fixation, ranged from 0.946 (cv. Pamiaty Rodinoy) to 1.148 arbitrary units (cv. Belgorodsky 100), averaging 1.020 units (CV on cultivars was $6.5 \%$ ).

The results of the calculation of integrated indices of PSII action efficiency for the studied barley cultivars are presented in Table 3.

Table 3. Performance indices of the PSII activity in studied barley cultivars.

\begin{tabular}{|c|c|c|}
\hline Cultivar & $\mathrm{PI}_{\mathrm{ABS}}$ & PI $I_{\text {ABS total }}$ \\
\hline Forward & $3.011 \mathrm{~b}$ & $1.508 \mathrm{~cd}$ \\
\hline Fermer & $2.085 \mathrm{a}$ & $0.846 \mathrm{a}$ \\
\hline Belgorodsky 100 & $2.961 \mathrm{~b}$ & $1.335 \mathrm{bc}$ \\
\hline Bionic & $2.736 \mathrm{~b}$ & $1.219 \mathrm{~b}$ \\
\hline Boyarin & $2.729 \mathrm{~b}$ & $1.386 \mathrm{bc}$ \\
\hline Dobryak & $2.859 \mathrm{~b}$ & $1.441 \mathrm{bcd}$ \\
\hline Novichok & $2.045 \mathrm{a}$ & $1.688 \mathrm{~d}$ \\
\hline Rodnik Prikamiya & $2.178 \mathrm{a}$ & $2.153 \mathrm{e}$ \\
\hline Pamiaty Rodinoy & $2.203 \mathrm{a}$ & $1.361 \mathrm{bc}$ \\
\hline Coefficient of variation, $\%$ & 15.7 & 24.6 \\
\hline
\end{tabular}

Note: the values followed by the same letters do not differ statistically according to the Duncan's test at $\mathrm{p} \leq 0.05$.

Table 3 shows that the second index allows for a clearer division of cultivars by PSII performance than the first. At the same time, the cv. Fermer can be distinguished as transmitting the least part of the absorbed energy in the PSI, and the cv. Rodnik Prikamiya as the most effective in this regard.

Using different parameters of PSII structure and functioning simultaneously it is possible to divide cultivars into similarity groups using a procedure of cluster analysis. To do this, we used the following eight indicators: ABS/RC, TRo/RC, ETo/RC, DIo/RC, $\delta_{\mathrm{RE}}$, $\psi_{\mathrm{RE}}, \mathrm{Fv} / \mathrm{Fo}$ and time to reach Fm. The results obtained by dividing the studied barley cultivars into clusters are presented in Figure 2. 


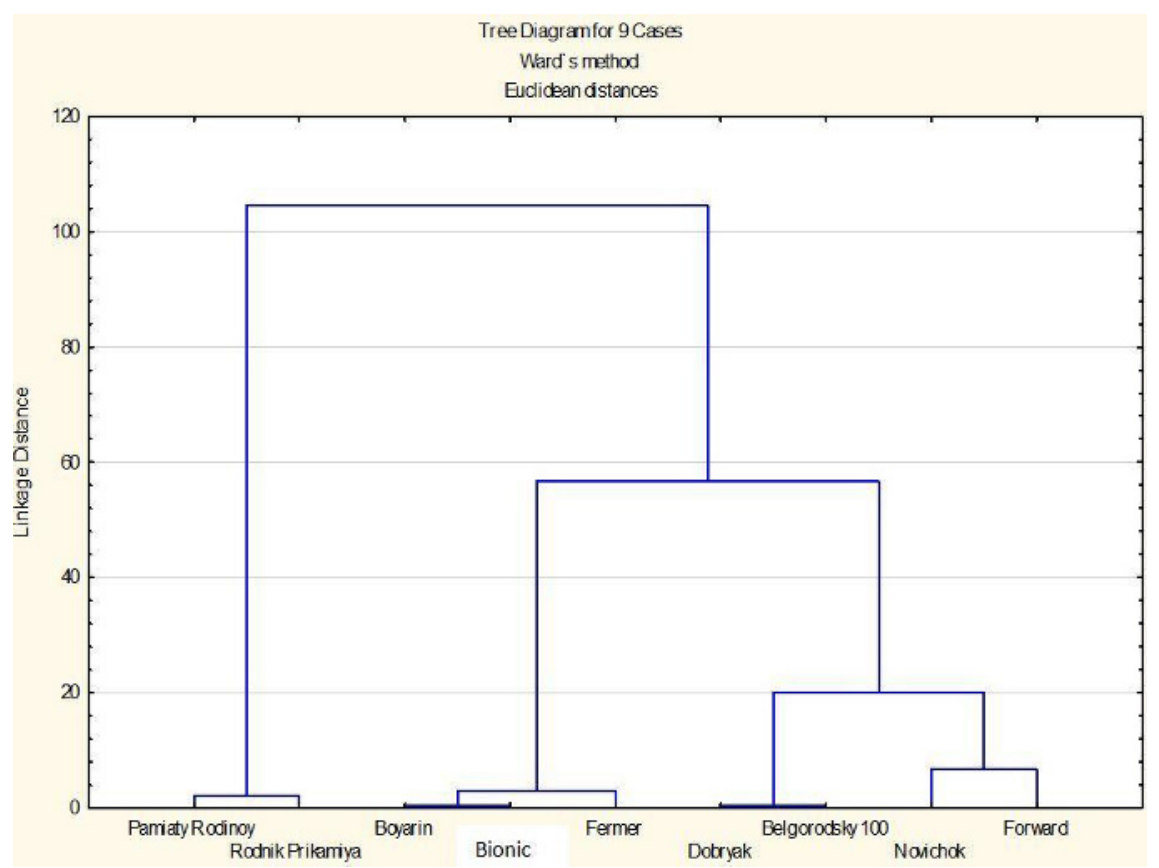

Fig. 2. Distribution of studied barley cultivars by clusters taking into account eight parameters of PSII activity.

As follows from the data of Figure 2, the most similar in PSII structural and physiological parameters are the cv. Boyarin and Bionic; Dobryak and Belgorodsky 100. At the same time, the cv. Pamiaty Rodinoy and Rodnik Prikamiya are as different as possible from other tested varieties. The cv. Boyarin and Bionic is very close to the cv. Fermer; a little less similarity is between the cv. Novichok and Forward.

\section{Discussion}

Since the level of the initial fluorescence (Fo) is due to the loss of energy during its transfer inside the antenna complex until the PSII reaction centers [12], light-harvesting complexes in the first five cultivars (Figure 1A) work more efficiently than in the remaining cultivars. The transfer of excitation energy between pigment molecules in the PSII light-harvesting antenna can deteriorate in stressful situations, for example, under thermal stress [12] or salinity [13], when tylacoid damage or dissociation of LHCII from the PSII nucleus occurs [14].

Since stressful situations were not created in our study, it can be stated that in chloroplasts of cv. Rodnik Prikamiya, Novichok, Fermer, Dobryak, and Pamiaty Rodinoy, light-harvesting complexes work more efficiently than in other cultivars. The maximum number of reaction centers that are capable of receiving excitation energy can be estimated by the maximum fluorescence parameter $(\mathrm{Fm})$. According to this parameter, in a set of studied cultivars, one can distinguish the cv. Boyarin, which had the maximum parameter value, and the cv. Rodnik Prikamiya, in which the value of this parameter was minimal.

The parameter of time for achieving maximum fluorescence most often has a value of $500 \ldots 800 \mathrm{~ms}$ [15] and characterizes the size of the pool of oxidized quinones. An increase in this parameter is associated with a slowdown in the transfer of high-energy electrons between reaction centers and plastoquinone molecules [16]. According to this parameter, significant cultivar diversity has been revealed: in chloroplasts of the cv. Fermer, Bionic 
and Boyarin, electron transport was carried out at a much faster rate than in the cv. Rodnik Prikamiya and Pamiaty Rodinoy.

For the total characteristic of the physiological state of plants, most investigators use the parameter of maximum photochemical efficiency of PSII $(\mathrm{Fv} / \mathrm{Fm})$, which normally should not be lower than 0.740 [3]. Some researchers find a linear relationship of this parameter with the rate of carbon fixation [17], although other works indicated that there is no such dependence [3, 18]. In a set of studied genotypes, the cv. Novichok is distinguished as having the least active reaction centers, while its level of activity is at the lower limit of the norm for plants that do not suffer any stress. The remaining cultivars showed parameter values characterizing the good state of the organism $(0.796 \ldots 0.801)$.

The Fv/Fo parameter is used to evaluate the ability of PSII antenna complexes of plant leaf chloroplasts to capture excitation energy (photons) [19]. The variability of the parameter in the studied set of cultivars was $9.9 \%$ that allowed to distinguished different cultivars: the antenna chlorophylls in leaf of cv. Novichok were the least capable and in leaves of cv. Forward and Belgorodsky 100 were the most capable of capturing photons.

The energy flow absorbed by one reaction center (ABS/RC index) simultaneously serves as an indicator of the size of the antenna complexes. In the studied set of cultivars, the difference between the cv. Novichok the most supplied with antenna pigments, and the cv. Forward and Farmer least provided with them was $16.3 \ldots 18.4 \%$. However, the ineffective costs of energy (DIo/RC) in the cv. Novichok was highest; cv. Farmer and Forward spend $31.3 \ldots 34.9 \%$ less energy on thermal radiation. Trapped energy in the form of a TRo/RC flux is transferred to the reaction centers and converted there to redox energy by oxidation of the primary acceptor $\mathrm{Q}_{\mathrm{A}}$, which is then re-oxidized into the initial form, thus creating an electronic transport flux $\mathrm{ETo} / \mathrm{RC}$, which ultimately leads to fixation of the $\mathrm{CO}_{2}$ [20]. In the studied set of barley cultivars, the share of the ETo/RC flux in the total absorbed energy ranged from 42.6 (cv. Pamiaty Rodinoy) to $52.9 \%$ (cv. Belgorodsky 100), averaging $46.8 \%$.

For a total characteristic of photosynthetic activity of PSII it is offered to use in practice of Tolerance Index (TI) [21] which summarized the main processes coming in PSII at adsorption of photons from antenna complexes to a secondary acceptor of the electrons (plastoquinon $\mathrm{Q}_{\mathrm{B}}$ ): efficiency of photons absorption (i.e. the ABS index), efficiency of capture of excitation energy (TR index), and efficiency of energy use in an electron transport chain (ET index). In [22], this index is designated as the Performance Index $\left(\mathrm{PI}_{\mathrm{ABS}}\right)$ and its modification is proposed, taking into account the efficiency of energy transfer to PSI ( $\left.\mathrm{PI}_{\mathrm{ABS} \text { total }}\right)$. According to the data in Table 3 it is possible to conclude that genotypic efficiencies of energy conservation at its transfer within PSII ( $\mathrm{PI}_{\mathrm{ABS}}$ ) and beyond PSII limits ( PI $_{\mathrm{ABS}}$ total $)$ differ considerably. Therefore, when considering only PSII, it can be noted that all cultivars were divided into 2 almost equal groups; if one considers the second index, then the cv. Fermer is allocated as transmitting the least part of the absorbed energy in the PSI, and the cv. Rodnik Prikamiya as the most effective in this regard. Since the variability of the second index is much higher than that of the first index, the $\mathrm{PI}_{\mathrm{ABS}}$ total index has great breeding value.

Since cluster analysis takes into account eight different parameters simultaneously, it seems logical to consider that cultivars combined into one cluster use approximately the same strategy of PSII activity, differing only in the quantitative manifestation of this strategy. Therefore, for example, the cv. Novichok and Forward significantly differed in the level of manifestation of most used parameters. The same is true for the cv. Fermer, on the one hand, and the cv. Boyarin and Bionic, on the other hand. Therefore, the involvement in crossbreeding of cultivars belonging to the same cluster will most likely not bring new combinations of genes that control the manifestation of these parameters. More promising 
is the use of barley cultivars distributed in different clusters in breeding work to increase the efficiency of leaf photosystem II activity.

\section{Conclusion}

Thus, the study showed the existence of statistically significant differences between spring barley cultivars on structural and functional parameters of the action of PSII in leaves of two-week-old seedlings. For each of the parameters, the studied set of varieties can be divided into three to four groups. The variability of the parameters used varied from 2.2...2.5 (size of the pool of oxidized quinones and maximum photochemical efficiency) to $24.6 \%$ (performance index $\mathrm{PI}_{\mathrm{ABS} \text { total }}$ ). Parameters characterizing the values of excitation energy fluxes within PSII (ABS/RC; TRo/RC; ETo/RC indices) varied to a small extent $3.1 \ldots 6.5 \%$, while the proportion of energy emitted as fluorescence and heat (DIo/RC index) is much stronger - $14.6 \%$. The efficiency with which electrons are transferred from the secondary acceptor $\mathrm{Q}_{\mathrm{B}}$ and generally from the PSII to the primary acceptors of PSI ( $\delta_{\mathrm{RE}}$ and $\psi_{\mathrm{RE}}$ parameters) varied even more - 18.1 and $17.4 \%$, respectively. The $\mathrm{PI}_{\mathrm{ABS}}$ integral performance index, reflecting the efficiency of the PSII energy transmission process, combined cultivars into two groups; but the $\mathrm{PI}_{\mathrm{ABS} \text { _total }}$ index, which also takes into account the efficiency of energy transfer until PSI, made it possible to divide cultivars into more different groups.

Cultivars Novichok and Fermer were significantly inferior to cultivars Forward, Belgorodsky 100, Boyarin and Bionic in most of the studied parameters. However, according to the results of a cluster analysis taking into account the eight main parameters of the PSII activity, the cv. Novichok and Forward turned out to be similar to each other, as well as the cv. Fermer, Boyarin and Bionic which separated into the same cluster. Probably, the action of PSII in the cultivars of the same cluster differs only quantitative but not qualitative; so for breeding work on pyramidizing the genes controlling the activity of this photosystem, it is advisable to crossing cultivars belonging to different clusters.

\section{References}

1. M.H. Kalaji, E. Woejko, T. Loboda, S. Pietkiewicz, Z. Wyszyski, Zesz. Probl. Post Nauk Roln., 496 (2004)

2. H.K. Lichtenthaler, U. Rinderle, CRC Critical Rev. Anal. Chem., 19, 1 (1988)

3. V. N. Goltsev, H. M. Kalaji, M. Paunov, W. Bąba, T. Horaczek, J. Mojski, H. Kociel, S. I. Allakhverdiev, Russian Journal of Plant Physiology, 63, 6 (2016)

4. M. Rapacz, M. Wójcik-Jagła, A. Fiust, H.M. Kalaji, J. Kościelniak, Front. Plant Sci., 78, 1 (2019)

5. C. Jedmowski, A. Ashoub, O. Momtaz, W. Brüggemann, J. of Botany (2015)

6. N. L. Pshybytko, T. S. Bachyshcha, L. F. Kabashnikova, Proceedings of the National Academy of Sciences of Belarus, Biological Series, 65, 2 (2019)

7. A. Dorsaf, B.-A. Anis, A. Chedly, J. Plant Nutrit., 41, 4 (2018)

8. G. Żurek, K. Rybka, M. Pogrzeba, J. Krzyżak, K. Prokopiuk, PLoS ONE, 9, 3 (2014)

9. N.-O. Bertholdsson, Agronomy, 3 (2013)

10. H.M. Kalaji, A. Rastogi, M. Živčák, M. Brestic, A. Daszkowska-Golec, K. Sitko, K.Y. Alsharafa, R. Lotfi, P. Stypiński, I.A. Samborska, M.D. Cetner, Photosynthetica, 56, 3 (2018) 
11. T. Warzecha, E. Skrzypek, T. Adamski, M. Surma, Z. Kaczmarek, A. Sutkowska, Plant Pathol. J., 35, 2 (2019)

12. A. Murkowski Oddziaływanie czynników stresowych na luminescencję chlorofilu w aparacie fotosyntetycznym roślin uprawnych (Inst. Agr. named aft. Bohdana Dobrzańskiego PAN, 2002)

13. M. Kalaji, A. Rutkowska, Zesz. Probl. Post. Nauk Rol., 496 (2004)

14. M. Havaux, Plant Cell Environ., 16, 4 (1993)

15. H. Lichtenthaler, C. Buschmann, M. Knapp, Analytical methods in plant stress biology (The Franciszek Gorski Inst. Plant Physiol., Polish Academy of Sciences, Krakow, Poland, 2004)

16. R.M.J. Reigosa, O. Weiss, Handbook of Plant Ecophysiology Techniques (Acad. Publ., Dordrecht, the Netherlands, 2001)

17. T.V. Nesterenko, V.N. Shikhov, A.A. Tikhomirov, Biology Bulletin Reviews, 80, 3 (2019)

18. N.A. Mir, R. Perez, R.M. Beaudry, International Postharvest Science Conference Postharvest (New Zealand, 1996)

19. A.A. Volgusheva, O.V. Yakovleva, I.B. Konyukhov, G.Yu. Riznichenko, T.E. Krendeleva, T. Gunn-Aajav, O.S. Bordanova, Ch. Battulga, A.B. Rubin, Mathematics, Computer Education, 2 (2009)

20. D.N. Matorin, A.B. Rubin, Fluorescence of chlorophyll of higher plants and algae (Moscow-Izhevsk, Institute for Computer Research, 2012)

21. M.A. Gururani, J. Venkatesh, M. Ganesan, R.J. Strasser, Y. Han, J.-I. Kim, H.-Y. Lee, P.-S. Song, PLoS ONE, 10 (2015)

22. P. Giorio, M.H. Sellami, Plants, 10, 887 (2021) 